\title{
Interpreting the progressive eutrophication behind the world's largest macroalgal blooms with water quality and ocean color data
}

\author{
Qianguo Xing ${ }^{1}$ Luigi Tosi ${ }^{2}$ - Federica Braga ${ }^{2}$. \\ Xuelu Gao ${ }^{1} \cdot$ Meng Gao ${ }^{1}$
}

Received: 12 January 2015/Accepted: 11 March 2015/Published online: 21 March 2015

(C) The Author(s) 2015. This article is published with open access at Springerlink.com

\begin{abstract}
World's largest macroalgal blooms (MAB) caused by Ulva prolifera outbreak every summer in the Yellow Sea since 2007, which bring potential damage to regional marine environment and economics. Assessing the evolution of historic eutrophication status is of importance for exploring the reasons for the blooms. In this study, we used an area-weighted nutrient pollution index (AWCPI-NP) and ocean color data to assess temporal changes in eutrophication status in the Yellow Sea basin. Results show that significant shifts occurred from the pre-MAB phase (2001-2006) to MAB phase (2007-2012): the average AWCPI-NP was higher than that in the pre-MAB phase (2001-2006) by about $45 \%$; chlorophyll $a$ concentration, an indicator of eutrophication, increased by about $15 \%$ in the region of MAB. Meanwhile, in the Jiangsu Shoal, the origin place of the floating macroalgae, the annual in situ nutrient concentrations increased rapidly from 2000 to 2011. The result obtained through our approach highlights that the MAB in the Yellow Sea might be primarily linked to the progressive eutrophication. In order to reduce this hazard, policy makers should include this new knowledge for an effective countermeasure planning.
\end{abstract}

Keywords Macroalgal blooms · Water quality · Ocean color · SeaWIFS · MODIS · The Yellow Sea

1 Key Laboratory of Coastal Environmental Processes and Ecological Remediation, CAS, No. 17 Chunhui Road, Laishan District, Yantai 264003, China

2 Institute of Marine Sciences, National Research Council, Arsenale - Tesa 104, Castello 2737/F, 30122 Venice, Italy 


\section{Introduction}

The occurrence of large-scale macroalgal blooms (MAB) around the world aroused a global concern on the coastal marine environment. Specifically, this MAB caused adverse impacts on local coastal tourism, marine transportation, and commercial fisheries. Coastal eutrophication is the most evident explanation for the proliferation of macroalgae biomass (Smetacek and Zingone 2013), although there might be other reasons controlling the blooms such as lack of grazer and increase in aquaculture (Liu et al. 2009). Understanding the reasons for MAB is the basis for a correct plan of prevention, control, and mitigation actions.

Small-scale MAB occurred in the Yellow Sea at least since the summer of $1999(\mathrm{Hu}$ et al. 2010; Xing et al. 2015). However, because of their limited extent, these events never received public's attention until they suddenly presented a large scale of "hazard" in Qingdao in the summer of 2008 (Zhang et al. 2015), i.e., when the city was one of the site of the Olympic Games hence in the spotlight of the world.

Satellite image records revealed that large scale of MAB started from 2007 in the Yellow Sea (Keesing et al. 2011; Xing et al. 2011). These floating MAB have seriously impacted the Yellow Sea by covering hundreds of square kilometers of ocean surface in every summer. In the early May, i.e., at the early stages of bloom, the patches of floating algae Ulva prolifera originated from the turbid waters of Jiangsu Shoal usually drift southward along with the Jiangsu Coastal Current and enter the East China Sea. As the Northeast Asia monsoon becomes stronger, most of the floating macroalgae drift northwardly and reach the southern coast of Shandong peninsula in June and July, and they disappear in August (Xing et al. 2011). Due to the insufficient knowledge on the emerging of $\mathrm{MAB}$ and the reasons for their development, no effective measures are taken by the Chinese authorities to control the blooms, and the super floating MAB occur every summer from 2007, despite the spectacular presence in the coast of Qingdao in the summer of 2008.

In China, the status of coastal waters is regularly monitored and represented through the coastal water quality levels (WQLs) and their spatial distribution in the Marine Environmental Quality Bulletin (a government report). The WQLs have been dominated by the nutrient pollution, i.e., the total inorganic nitrogen (TIN-N) and the active phosphorus $\left(\mathrm{PO}_{4}-\mathrm{P}\right)($ SOA 2010, 2011, 2013). However, the sites of regular field monitoring always lie in nearshore waters. Therefore, there are no long time series of in situ measurements in the offshore waters, and the spatially discrete results are not suitable for the environment assessment at a basin scale. As reported by Xing et al. (2010), there is neither long-term data nor effective traditional approaches for the assessment of macroalgae-associated nutrient enrichment in the entire semi-enclosed region of the large Yellow Sea basin.

Chlorophyll $a$ (Chl- $a$ ), a phytoplankton pigment, is widely used as indicator in the assessment of eutrophication (Carlson 1977). The dynamics of phytoplankton is usually controlled by nutrients in aquatic ecosystem (Egge and Aksnes 1992; Gao and Song 2005); similarly for macroalgae, growth of Ulva ssp. and Enteromorpha spp. was highly related to the enrichment of nutrient (especially the nitrogen) as shown by experimental and numerical studies (Menesguen et al. 2006). However, the long-term records of in situ Chl$a$ are scarce because it is not a compulsory parameter in the marine environmental monitoring procedures in China (Qu et al. 2006). Alternatively, archive satellite data have considerable potential in providing historical environmental trends since they are regularly collected. Hence, remote sensing techniques are often successfully used for assessing 
marine environmental parameters (Liu et al. 2014), especially in the offshore waters where in situ measurements require oceanographic cruises that are relatively few in number.

In order to understand the causes of the presence of large-scale MAB in the Yellow Sea, it is essential to know the status and the trend of nutrient enrichment before and after their occurrence. Previous studies (e.g., Liu et al. 2012, 2013 and therein) discussed the nutrient pollution; however, they could not indicate how was its evolution behind the MAB in the Yellow Sea.

In this paper, we use satellite-derived Chl- $a$, sea surface temperature (SST), and photosynthesis active radiation (PAR) to analyze the change and trend of eutrophication in the Yellow Sea. In addition, a novel index combining the area of nutrient-polluted marine waters and their corresponding level is used to evaluate the entire regional nutrient pollution status of coastal waters and to explore the process of eutrophication behind the super MAB.

\section{Data and methods}

\subsection{Studied area and field work}

The Yellow Sea (Fig. 1a) is a semi-enclosed coastal sea with an area of $380,000 \mathrm{~km}^{2}$ connecting the Bohai Sea with open waters - the East China Sea; the Bohai Sea with an area of about $77,000 \mathrm{~km}^{2}$ may also be considered to be part of the large Yellow Sea ecosystem (UNDP 2007).

As consequence of the rapid economic development of China started from the last decades, the coastal areas of the Yellow Sea have experienced strong anthropogenic impact because of the new urbanization and growth of economic activities such as industry, agriculture, and aquaculture. Coastal anthropization resulted in large amounts of nitrogen and phosphorus as well as other pollutants have been discharged into the basin, and the

(a)

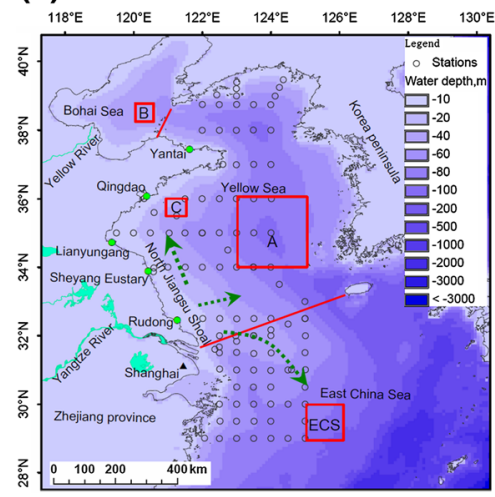

(b)

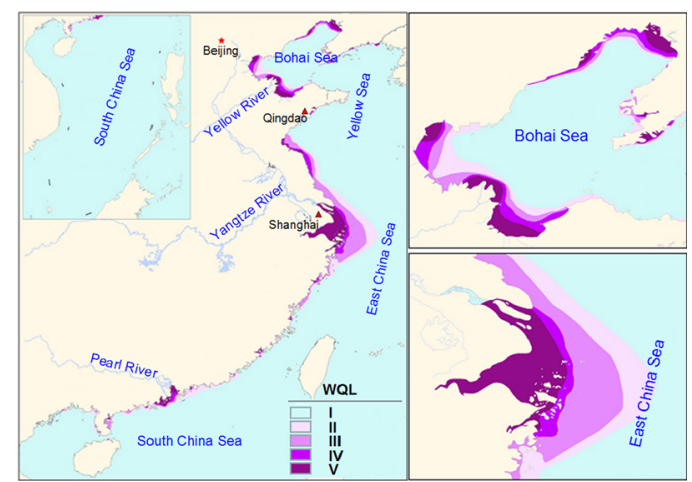

Fig. 1 a Study area of the Yellow Sea and its vicinity. Green arrows show the major drifting pathways of floating macroalgae (Xing et al. 2011); the four red boxes show the locations where satellite-derived Chl$a$ concentration was extracted; the red lines show the northern and southern boundaries of the Yellow Sea. The white circles show the field observation sites sampled in 2009 (15 May-19 June), and the green bullets indicate the sites of macroalgae observation on the tidal flats. b Example of water quality levels (WQL) of China coastal water quality levels in 2007 (source: SOA, China) 
aquatic ecological system has been facing a serious problem of degradation (SOA 2010). Green MAB were investigated both in tidal flats and in offshore waters. In 2007, 2008, 2010, and 2014, the location of macroalgae blooms and their type were recorded at the coast of Yantai, Qingdao, and the North Jiangsu Shoal. The presence of floating green macroalgae was detected in the offshore waters of the Yellow Sea and the East China Sea, during an oceanographic cruise from May 15 to June 19, 2009. The location of stations is shown in Fig. 1a.

\subsection{Area-weighted water quality level}

Eutrophication index or composite pollution index (CPI) can be used to evaluate the pollution status of a given water body, especially with the issue of eutrophication (Lund 1967; SOA 2011; Zou et al. 1985; Chen et al. 2007). Coastal water quality in China is dominated by nutrient pollution (SOA 2010, 2011, 2013), and, in order to evaluate the overall water quality status in regional waters which can be classified as different water bodies with different WQLs, an area-weighted nutrient pollution index (AWCPI-NP) is proposed in this study (Eq. 1):

$$
\text { AWCPI-NP }=\sum_{i=2}^{5}\left(N_{i} \cdot P_{i} \cdot A_{i}\right)
$$

where $i$ is the WQL of polluted waters (see Fig. 1b for an example of China coastal WQLs in 2007), $N_{i}$ is the lower limit of TIN-N concentration $(\mathrm{mg} / \mathrm{L})$ at the level $i, P_{i}$ the lower limit of $\mathrm{PO}_{4}-\mathrm{P}$ concentration $(\mathrm{mg} / \mathrm{L})$ at the level $i$ (Table 1$)$, and $A_{i}$ is the corresponding area of water body at this level $\left(\mathrm{km}^{2}\right)$. WQL $(i)$ and its area $(A i)$ were collected from the annual reports of SOA, China, and they are available from 2001. TIN and PO4-P as well as other marine environmental parameters along China coasts were regularly measured on water samples according to China standard marine sampling and measuring protocols (GB17378.4-1998) (Qu et al. 2006; SOA 2011). At each site, water samples were collected at the surface $(0.5 \mathrm{~m}$ depth $)$, middle, and bottom ( $0.5 \mathrm{~m}$ above the sea floor) layers. The concentration of each parameter was obtained by averaging the values of the three layers. These data were reprocessed in a regular grid by the Kriging interpolation method for obtaining the map of their 2D horizontal distributions. Finally, according to the limits for environmental parameters, e.g., TIN and $\mathrm{PO}_{4}-\mathrm{P}$ shown in Table 1, the area of each level (A) was calculated.

As aforesaid, since the data of WQL ( $i$ and $A_{i}$ ) were collected in annual reports by SOA only from 2001, the yearly AWCPI-NP obtained by Eq. 1 refers to the 2001-2012 period. In addition, because water quality data of coastal waters for Yellow Sea and Korean

Table 1 TIN and $\mathrm{PO}_{4}-\mathrm{P}$ concentrations used for calculation of AWCPI-NP

\begin{tabular}{lllll}
\hline Water quality level & I & II & IV & V \\
\hline TIN $\left(\mathrm{mg} \mathrm{L}^{-1}\right)$ & 0.2 & 0.3 & 0.4 & 0.5 \\
$\mathrm{PO}_{4}-\mathrm{P}\left(\mathrm{mg} \mathrm{L}^{-1}\right)$ & 0.015 & 0.030 & 0.030 & 0.045 \\
\hline
\end{tabular}

\footnotetext{
${ }^{a}$ Water quality levels II, III, IV, and V are corresponding to relatively clean water, slightly polluted water, medium polluted water, and heavily polluted water, respectively. And, level V has only a lower limit of the concentration of each pollutant (MEP 1997)
} 
Peninsula are not available, the AWCPI-NP was calculated on the base of the water quality data of China. This has been done on the base taking into account population, watershed, and related factors, and assuming that AWCPI-NP at the western Korean coastal waters would not decrease. For this reason, it is reasonable to think this assumption not significantly influenced the results of time series analysis.

\subsection{Mapping floating macroalgae}

Floating macroalgae have spectral characteristics similar to those of vegetation, and the widely used normalized difference vegetation index (NDVI) or other similar indices (Shi and Wang 2009; Garcia et al. 2013) can be used to extract the macroalgae patches. It should be noted that studies using different spatial resolution images and difference indices (e.g., Liu et al. 2009; Xing et al. 2011; Keesing et al. 2011; Garcia et al. 2013) could give different results on covering area of floating macroalgae.

In this work, to keep the consistency with our previous results (e.g., Liu et al. 2009; Xing et al. 2011), Moderate-Resolution Imaging Spectroradiometer (MODIS terra/aqua) reflectance products with a resolution of $500 \mathrm{~m}$ are used. After MODIS imageries were georeferenced, the bands $1 \#(840-875 \mathrm{~nm})$ and 2\# $(620-670 \mathrm{~nm})$ were used to generate the NDVI images and the NDVI was calculated (Eq. 2).

$$
\text { NDVI }=(\text { band } 1-\text { band } 2) /(\text { band } 1+\text { band } 2)
$$

A threshold value of NDVI was set to identify the floating macroalgae patches; due to the impacts from clouds, haze, sun glints, and water background, a strategy of dynamic NDVI threshold was applied to extract macroalgae patches (Xing et al. 2011; Cui et al. 2013). Finally, the maximum MODIS-derived daily distributions of macroalgae were calculated for the 2007-2013 period.

\subsection{Satellite-derived data}

The annual Chl- $a$ concentration with a $9 \mathrm{~km} \times 9 \mathrm{~km}$ spatial resolution was obtained from the satellite imaging products of Sea-Viewing Wide Field-of-View Sensor (SeaWIFS) and MODIS aqua (data available: http://oceancolor.gsfc.nasa.gov). The Chl- $a$ data were derived from SeaWiFS and MODIS aqua imagery on the basis of the algorithm developed by O'Reilly et al. (1998). The high load of suspended sediments, mainly due to river discharge and sediment re-suspension in shallow waters in the Yellow Sea, could lead to overestimate in satellite-derived Chl- $a$ (Yamaguchi et al. 2012). In order to reduce the uncertainties in analysis, which might be brought by the inaccurately estimated Chl- $a$ in turbid waters, we extracted the average of Chl- $a$ at the middle of the Yellow Sea $\left(123-125^{\circ} \mathrm{E}, 34-36^{\circ} \mathrm{N}\right)$ as well as the Bohai Sea $\left(120-120.5^{\circ} \mathrm{E}, 38.25-38.75^{\circ} \mathrm{E}\right)$ considering the 1998-2012 period (Fig. 1): (a) MODIS data: 2002-2012 and (b) SeaWIFS: 19982010. The systematic bias between the SeaWIFS Chl- $a$ and the MODIS Chl- $a$ was corrected with the regression equation between MODIS and SeaWiFS monthly Chl- $a$ (Eq. 3). They were spatially and temporally matched, and then, the corrected SeaWIFS Chl- $a$ from 1998 to 2002 and the MODIS Chl- $a$ from 2003 to 2012 were used to generate a yearly time series of satellite-derived Chl- $a$.

$$
\text { SeaWIFS Chl- } a, \mu \mathrm{g} / \mathrm{L}=1.0772 \times \text { MODIS Chl- } a+0.0961
$$


Monthly SST and PAR detected by MODIS terra were used for investigating the water temperature and solar radiation (data available: http://oceancolor.gsfc.nasa.gov).

\section{Results and discussion}

\subsection{World's largest super floating macroalgae blooms (MAB)}

The maximum daily covered areas derived from 2007 to 2013 MODIS satellite imageries show that floating macroalgae mainly occurred in the west of the Yellow Sea and to the north of the Jiangsu Shoal (Fig. 2). The Jiangsu Shoal was the source of macroalgae, and its waters were highly eutrophicated due to the nutrient input discharge of anthropogenic activities (Liu et al. 2012), but the turbid water with a Secchi depth of about $0.1 \mathrm{~m}$ limited the rapid growth of macroalgae (Xing et al. 2011).

Particulary from 2008, the bloom scale increased several to tenfold. In the summer of 2008, the world's largest MAB of $U$. prolifera drifted from the middle of southern part of the Yellow Sea and hit the Qingdao City (Xing et al. 2009; Liu et al. 2009; Zheng et al. 2011) covering an area of $1200 \mathrm{~km}^{2}$ in total (Table 2) and impacting as many as
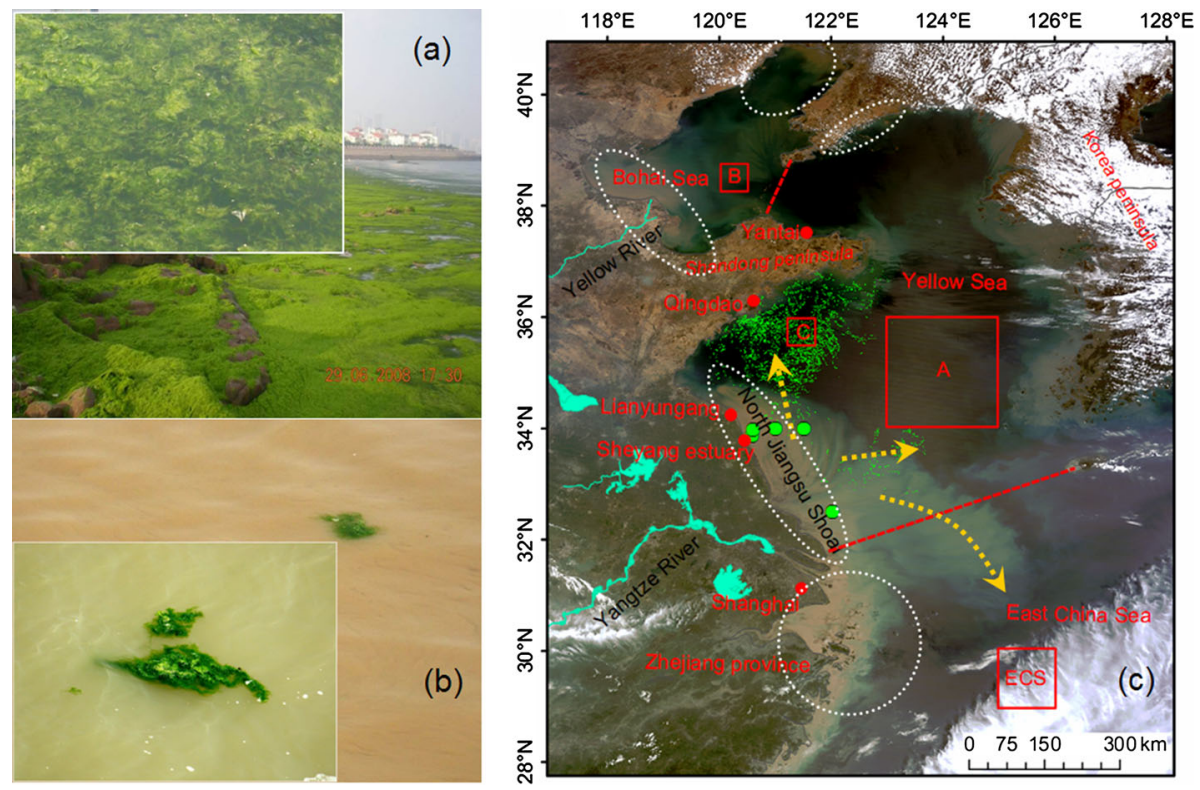

Fig. 2 In situ photographs of Ulva prolifera of green algae a covering the beaches in Qingdao on June 29, 2008 (photograph by Qianguo Xing and Xianzheng Yuan), and b floating in the Northern Jiangsu Shoal (photograph by Qianguo Xing and Yanju Hao). c Map of the spatial distribution of the green tide. Green patches are the sites of the annual maximum daily covering area of macroalgae from 2007 to 2013; green dots indicate the locations where macroalgae were validated in the cruise in the May of 2009; brown arrows show the major drifting pathways of floating macroalgae; the four red boxes show the locations where satellite-derived chlorophyll concentration was extracted; the red dash lines show the boundary of the Yellow Sea; the white dot circles show the major polluted sites; and the background image (generated by Qianguo Xing) is a true color composite of bands 1(R), 4(G), 3(B) of MODIS acquired on March 31, 2010 (http://ladsweb.nascom.nasa.gov/) 
Table 2 Satellite-derived annual maximum daily covering areas of floating macroalgae

\begin{tabular}{llc}
\hline Year & Day-month & Covering area $\left(\mathrm{km}^{2}\right)$ \\
\hline 2007 & 17-June & 110 \\
2008 & 31-May & 1200 \\
2009 & 22-July & 860 \\
2010 & 9-July & $310^{\mathrm{a}}$ \\
2011 & 20-July & 700 \\
2012 & 21-June & $300^{\mathrm{a}}$ \\
2013 & 29-June & 1110 \\
\hline
\end{tabular}

$40,000 \mathrm{~km}^{2}$ of sea surface. Only from a part of the coast of Qingdao, more than 1,000,000 tons of biomass was collected (Xing et al. 2011). This bloom scale is much larger than any other places in the world, e.g., Italy, France, and Australia (Menesguen et al. 2006; Morand and Briand 1996), and the conservatively collected biomass of green algae in 2008 is also larger than that of floating sargassum in a recent large-scale bloom (Gower and King 2011; Gower et al. 2013).

Small-scale MAB covering area less than $60 \mathrm{~km}^{2}$ occurred in the Yellow Sea, at least since the summer of 1999. Hu et al. (2010) and Xing et al. (2015), using satellite images, reported that these marginal $\mathrm{MAB}$ were detectable only by high-resolution Landsat images (30 m pixel) while were not observable by the lower-resolution MODIS images (500 m pixel).

\subsection{Progressive eutrophication behind the MAB}

\subsubsection{Progressive nutrient pollution indicated by water quality}

In the semi-enclosed region of the Yellow Sea and the Bohai Sea, the polluted areas characterized by different WQLs fluctuated yearly without a significant trend during the 2001-2012 period (Fig. 3). In the Yellow Sea, the area of relatively clean waters (Level II) decreased by about $50 \%$, while the area of the heavily polluted waters (Level V) increased sharply. There were no significant trends in the polluted (Level IV) and slightly polluted waters (Level III), and from this information, it is difficult to assess the overall nutrient pollution status. The application of AWCPI-NP overcomes the previously used method with a group of WQLs and areas. The changes obtained in the Yellow Sea and the Bohai Sea (Fig. 3c, d) clearly show that both of them experienced an increase in nutrient pollution, especially the latter which increased onefold from 2001 to 2007.

The annual values of AWCPI-NP from 2001 to 2012 (Fig. 3c) show a significant high level of nutrient status since 2004 in the semi-enclosed region $(p<0.01, F$ test). The largescale floating MAB happened every summer since 2007, and the averaged AWCPI-NP in 2007-2012 (MAB phase) is larger by about $45 \%$ than that in 2001-2006 (pre-MAB phase) and nearly three times of that in 2001-2003. These results support that the eutrophicating process in the Yellow Sea might lead to the MAB. When the AWCPI-NP is normalized by the enclosed area, we can find that the Bohai Sea has a higher nutrient pollution status than the Yellow Sea (Fig. 3d).

Records (SOA 2013; JSOF 2011) show that polluted sea water in Jiangsu province (coastal water along the Jiangsu Shoal, Fig. 1) increased rapidly more than onefold from 2003 to 2011, and its contribution to the pollution in the Yellow Sea also increased, e.g., 

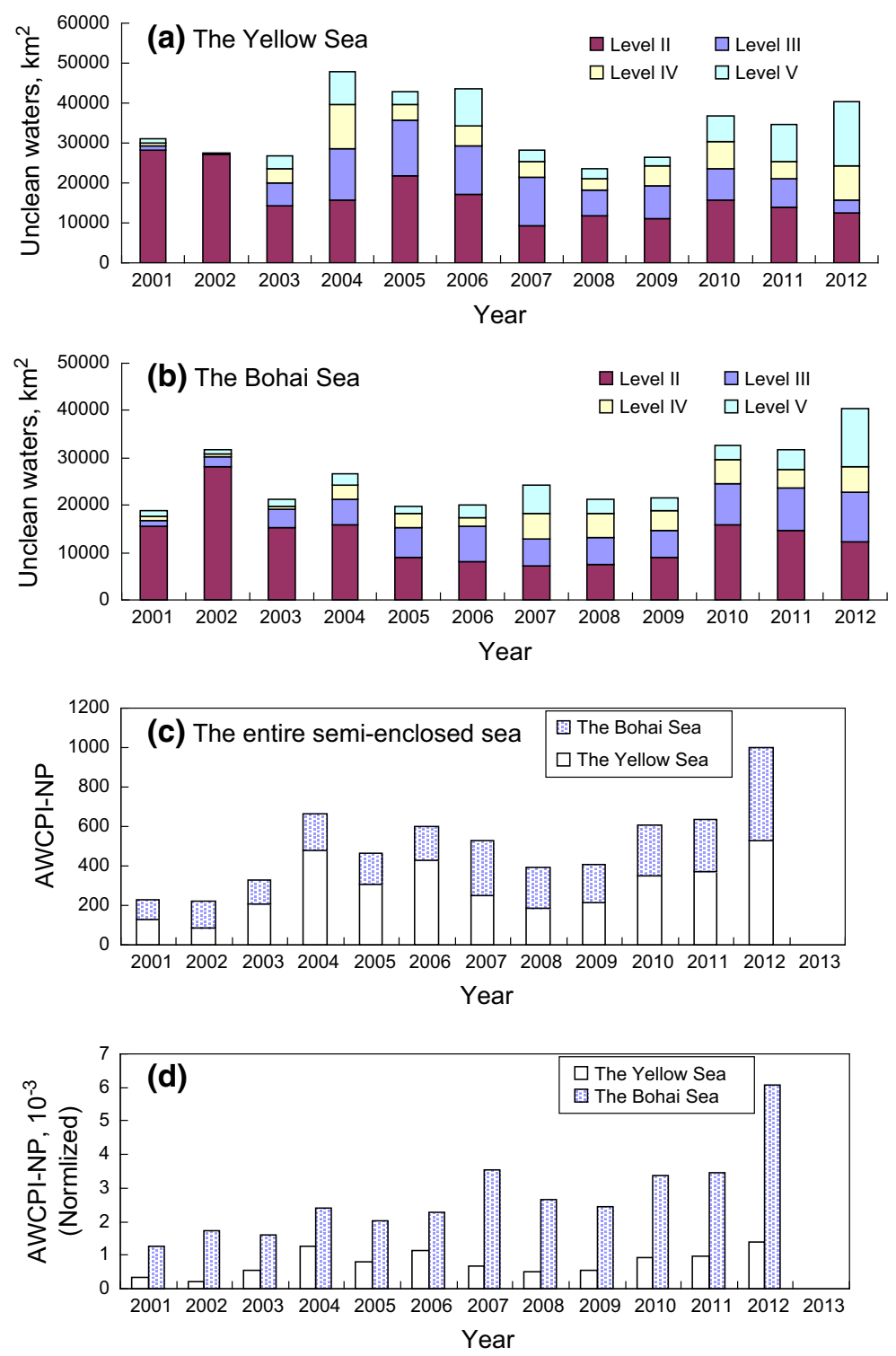

Fig. 3 a, b Changes in nutrient quality levels in the Yellow Sea and the Bohai Sea, respectively, c the AWCPI-NP in the entire semi-enclosed sea, and $\mathbf{d}$ the AWCPI-NP normalized by the areas of the Yellow Sea $\left(380,000 \mathrm{~km}^{2}\right)$ and the Bohai Sea $\left(77,000 \mathrm{~km}^{2}\right)$

more than $60 \%$ in 2007 (Fig. 4a). Meanwhile, the nitrogen and phosphorus concentrations increased significantly from 2000 to 2011 (Fig. 4b) especially the active phosphorus $\left(\mathrm{PO}_{4}-\mathrm{P}\right)$ increased threefold from 2000 to 2011. The Jiangsu Shoal is the "seedbed" providing the seeds of macroalgae which might be attached to the aquaculture facilities, tidal flat, or existed as germlings in seawater or sediments (Liu et al. 2009; Pang et al. 2010; Zhang et al. 2011); with this eutrophication, more seeds might be released under 
(a)

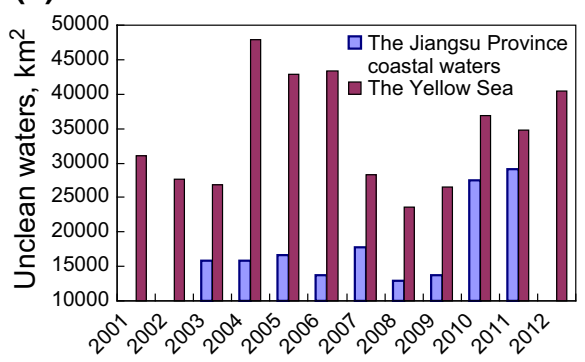

(b)

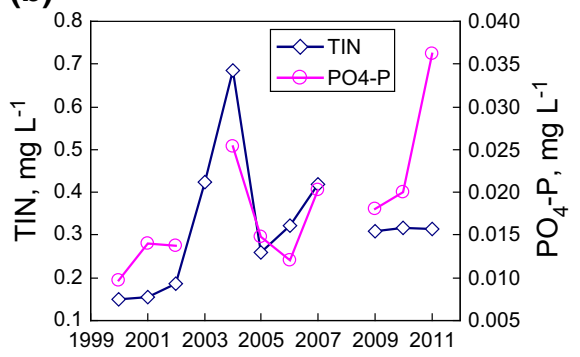

Fig. 4 Increasing trends in polluted area (a) and nutrient concentrations (b) in the Jiangsu Shoal behind the macroalgae blooms

human or natural disturbance, e.g., seaweed harvesting and bottom shears of tidal and/or wind-driven currents, and led to the world's largest super MAB in the Yellow Sea. Smaller scale of MAB with the covering area of lower than $60 \mathrm{~km}^{2}$ happened during the 1999-2006 period at the Yellow Sea and the East China Sea (Hu et al. 2010; Xing et al. 2015), which is consistent with the lower trophic status in that period. Moreover, the sudden increase in nutrient in 2004 (Fig. 4b) not only led to the increase in Chl- $a$ in that summer (Xing et al. 2015), but also might lead to the sudden presence of large scale of MAB in 2007 where a 3-year time lag might be due to the wintering and accumulation of U. prolifera progagules (Zhang et al. 2011; Smetacek and Zingone 2013).

\subsubsection{Eutrophication indicated by Chl-a}

As indicated by Chl- $a$ (Fig. 5), before the large-scale MAB (1998-2007), most of the Yellow Sea basin experienced a eutrophicating process (green patches in Fig. 5b). Chl$a$ had a pronounced increase in the centers of both the Yellow Sea $(p<0.01)$ and the Bohai Sea $(p<0.001)$ from 1998 to 2012 (Fig. 6a), while at the center of the Yellow Sea $(p<0.005)$ Chl- $a$ was much lower than that at the Bohai Sea. These results are consistent with the distribution of eutrophic status indicated by the AWCPI-NP, i.e., the overall eutrophic status of the large semi-enclosed basin, which suggests that the increase in phytoplankton biomass in 2001-2012 might be driven by the increase in nutrients. The

(a)

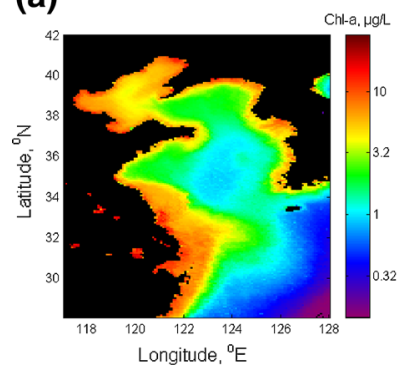

(b)

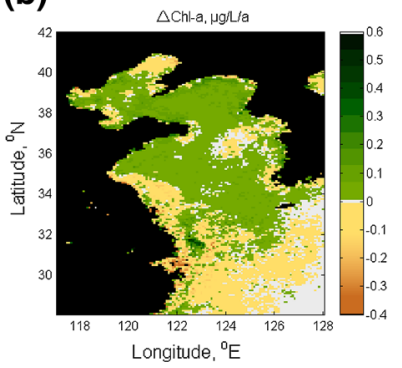

(c)

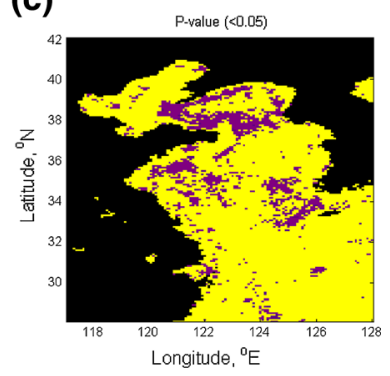

Fig. 5 Statistics in Chl- $a$ from 1997 to 2007 (pre-MAB): a mean of multi-year Chl- $a$; b linear trends in the changes in annual Chl- $a$ : $\Delta$ Chl- $a$ means the changing rate; and c significance test with the linear trends: pixels in purple have significant changes $(p<0.05)$ 
(a)

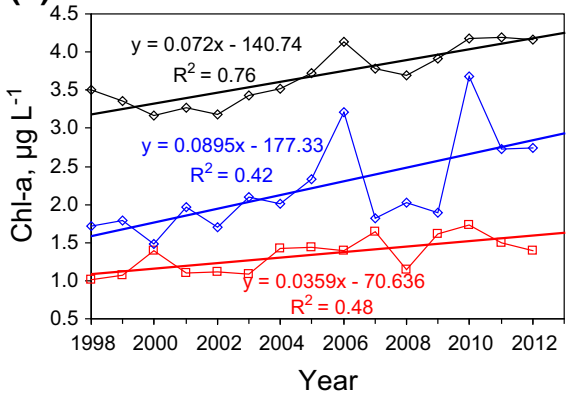

(b)

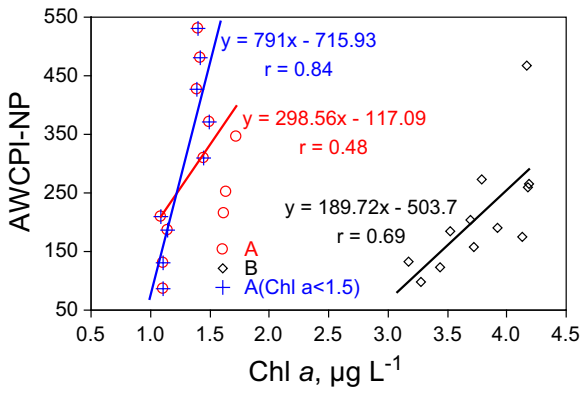

Fig. 6 a Increases in the satellite-derived Chl- $a$ from 1998 to 2012 in the Yellow Sea (red line), Bohai Sea (blue line), and Eastern China Sea (black line); $\mathbf{b}$ relation between Chl- $a$ and the AWCPI-NP of the Yellow Sea (a) and the Bohai Sea (b) in 2001-2012

Chl- $a$ in the west of southern Yellow Sea $\left(35.5-36^{\circ} \mathrm{N}, 121.25-121.75^{\circ} \mathrm{E}\right.$, Box C in Fig. 1), where super MAB occur every summer from 2007, also increased during the 1998-2012 period.

Compared with the inner part (the Bohai Sea, $p<0.01$ ) of the entire large Yellow Sea basin, a low correlation was observed between the Chl- $a$ and the AWCPI-NP in the outer part (the Yellow Sea) (Fig. 6b). This may be mainly due to the following reasons: (a) The AWCPI-NP in the Yellow Sea was not so soundly calculated (as mentioned in the section of methods); (b) the waters from the East China Sea may lead to the fluctuations in nutrients and temperature in the center of the Yellow Sea (Box A in Fig. 1); and (c) MAB may affect phytoplankton in the ways of nutrient competitions and so on. At the center of the Yellow Sea, the Chl- $a$ lower than $1.5 \mu \mathrm{g} / \mathrm{L}$ had a high correlation with the AWCPI-NP $(p<0.01)$ (Fig. 6b), which might imply that the waters with low eutrophic conditions were sensitive to the nutrient input.

The floating macroalgae could cause false values in the satellite-derived Chl- $a$ (Xing et al. 2015), i.e., pixels optically contaminated by floating macroalgae were not completely masked during the processing of standard Chl- $a$ product. Thus, Chl- $a$ values for these pixels were mistaken as phytoplankton-related Chl- $a$. The annual Chl- $a$ concentration in the MAB phase was higher than that in the pre-MAB phase by $16 \%$; when the months with possible impact of floating algae were excluded (June-August), a rise of $15 \%$ in Chl$a$ was still observed from the pre-MAB to MAB phase. These results suggest that a progressive eutrophication existed behind the super $\mathrm{MAB}$ and that the MAB did not change the eutrophication trend. Satellite-derived optical indices in addition to Chl- $a$ also suggested an increase in the portion of phytoplankton particles in the southern Yellow Sea (Xing et al. 2012).

As indicated by Chl- $a$, trophic status both in the middle southern Yellow Sea (Box A) and the offshore waters in the East China Sea (Box ECS in Fig. 1c) was lower than that in southwest of Yellow Sea (Box C), especially by $50 \%$ in the summer season. Macroalgae from the Jiangsu Shoal reached these two regions (Xing et al. 2011), but the bloom scales were very small. This suggests that trophic status regulated the scale of MAB in China coastal waters. 


\subsection{Changes in sea surface temperature (SST) and photosynthesis active radiation (PAR)}

Natural variations in water temperature and light conditions can lead to the changes in the growth of phytoplankton. The comparisons of SST and PAR between the pre-bloom phase (2001-2006) and the macroalgal bloom phase (2008-2013) point out that neither the SST nor the PAR had significant shift (Fig. 7). This fact suggests that SST and PAR were not likely the driving factors for the increase in phytoplankton or the outbreak of MAB.

The growth of macroalgae is not so sensitive to the seasonal variation in PAR as that in water temperature. The water temperature favorable for the growth of macroalgae $(U$. prolifera) is about $15^{\circ} \mathrm{C}$ (Liu et al. 2009). SST shows an increase in water temperature from winter (February) to summer (July) in the Yellow Sea and East China Sea and water temperature suitable for the rapid growth of macroalgae in the Yellow Sea in May, June, and July (Fig. 8a). However, from the pre-bloom phase (2001-2006) to the macroalgal bloom phase (2008-2014), the monthly SST decreased significantly at the most of the Yellow Sea basin especially in April, May, and June (Fig. 8b, c). This decrease in water temperature would suppress the growth of macroalgae, i.e., the occurrence of massive MAB since 2007 was not likely caused by the changes in the growth rate due to the water temperature.

\subsection{Discussion on the reasons for the super MAB}

Coastal zones in China have experienced a rapid process of urbanization and industrialization especially in the past 30 years since the beginning of opening-up economic policy in China (He et al. 2006). The reports on China's marine environment from 1992 to 2012 (SOA 2010, 2011, 2013) also showed that the total area of unclean waters increased in the past 20 years, which were mainly due to nutrient pollution. The Yellow Sea and the Bohai Sea experienced a large amount of nutrient input due to human activities such as agriculture and aquaculture, especially at the Jiangsu Shoal.

In this study, we showed that the eutrophication trend indexed by the Chl- $a$ was consistent with the contemporary increasing trend in the AWCPI-NP and the fact of the continuous super MAB in the Yellow Sea since 2007. The increase in Chl- $a$ in coastal waters has been noted to be likely driven by the local eutrophication due to the input of

(a)

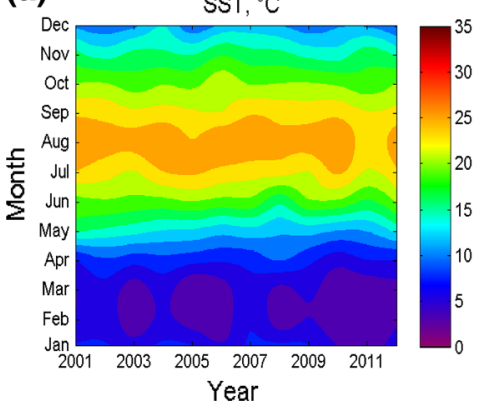

(b)

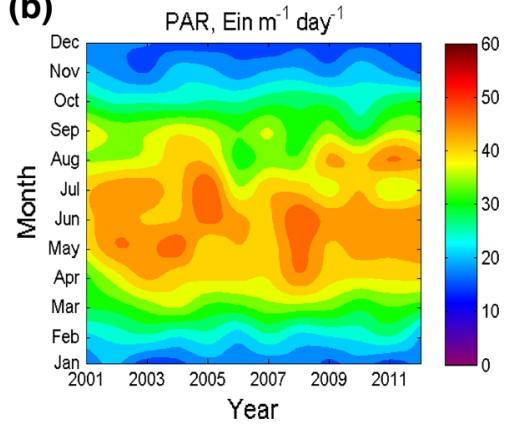

Fig. 7 Monthly SST and PAR in the period of 2001-2012 in the area with frequent occurrence of macroalgae (see location in Fig. 3c, box C) 


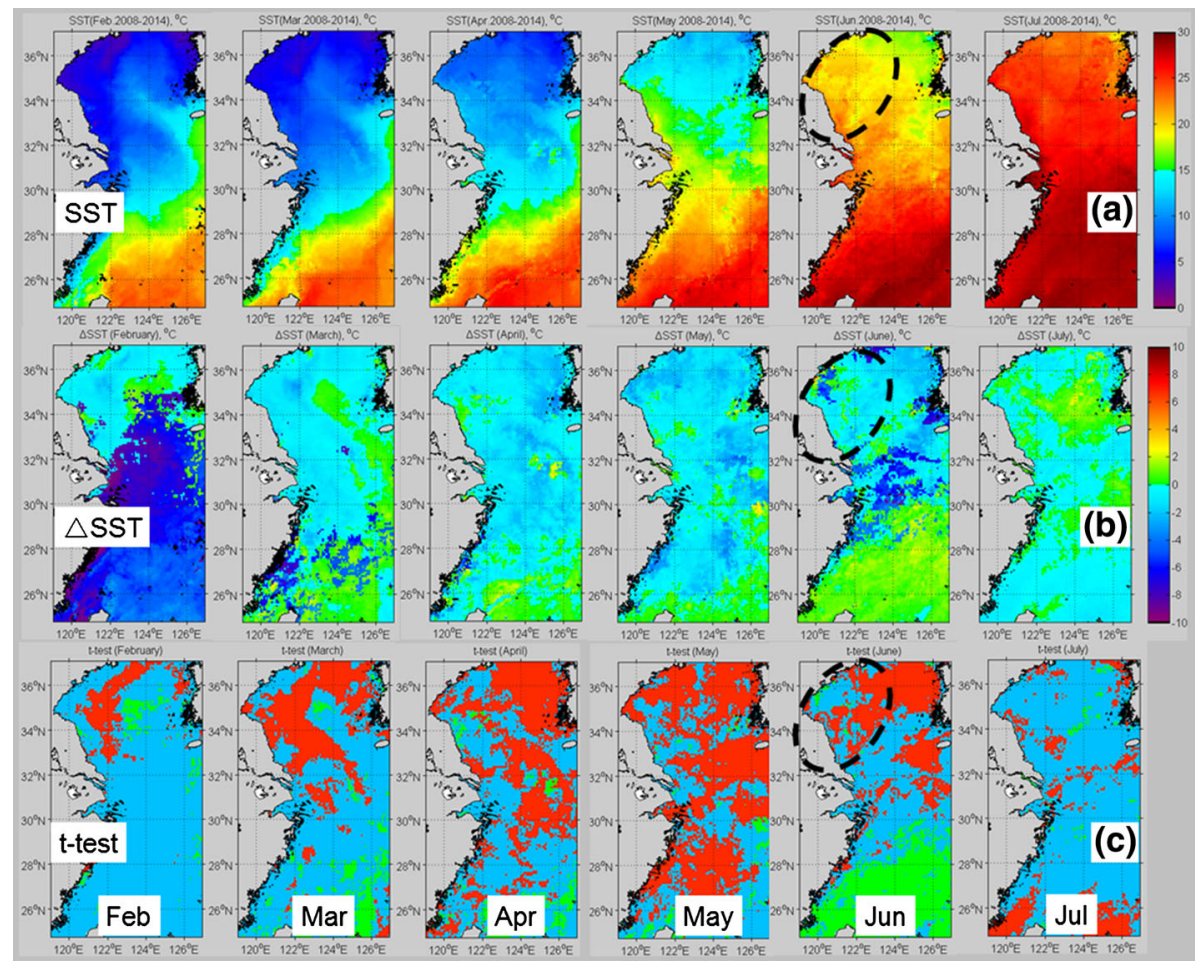

Fig. 8 a Multi-year means of monthly SST in the MAB phase (2008-2014); b shifts in multi-year mean SST from pre-MAB phase (2001-2006) to MAB phase (2008-2014); and $\mathbf{c}$ the significance testing with the means: The red means the significant decrease, the green means significant increase, and the blue means no significant change

excess nutrient because of human-induced activities, and the occurrence of super MAB might be due to the same reason. The agreement between the super MAB and the high levels of nutrient pollution implies that the progressive eutrophication might be the primary reason for the super MAB since 2007.

The expansion of "nori" (Pyropia yezoensis) aquaculture was also thought to be the primary reason for the world's largest MAB in the Yellow Sea (Liu et al. 2009; Hu et al. 2010): "Nori" aquaculture in the Jiangsu Shoal starts from August and ends in next April, which expanded in the past years; U. prolifera (MAB species) grows and attaches to the facilities of "nori" aquaculture, i.e., ropes, poles, and nets; and in April, large amount of macroalgae of $U$. prolifera is removed for the facilities and dispersed into sea water, which induces the super MAB. According to this viewpoint, there should be MAB before 2007 and their scales could be estimated by the scale of aquaculture (e.g., the area) to which the seed population (removed macroalgae) can be regarded to be linearly proportional (Smetacek and Zingone 2013), and, according to the estimation from the evolution of "nori" aquaculture at the Jiangsu Shoal (Fig. 9), the scales of MAB in 2005, 2006, 2007, and 2008 should be close (at least in a same order). However, super MAB abruptly occurred in 2007, 2 years before the sudden increase in aquaculture in $2009(\sim 100 \%$ from 2007), which implies that the expansion in aquaculture area was not likely the basic reason for the world's largest MAB since 2007. Increased aquaculture scale would not 


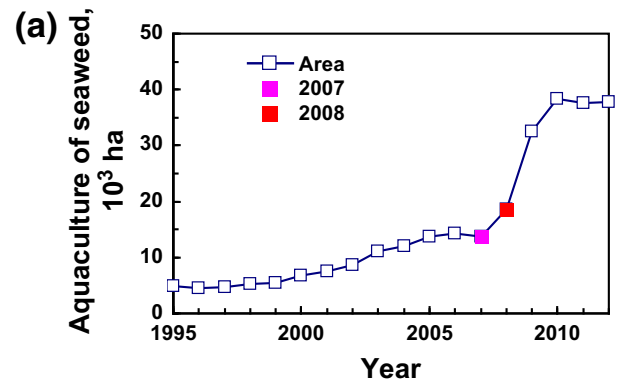

(b)

(c)
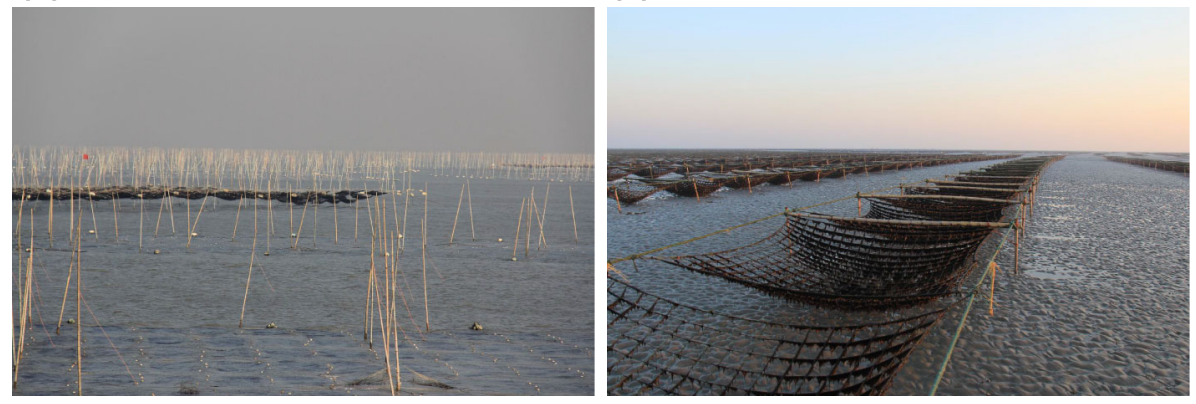

Fig. 9 a Aquaculture area of "nori" (Pyropia yezoensis) in the Jiangsu Shoal during the 1995-2012 period (Source: China Fisheries Statistical Yearbook). b, c Photograph of aquaculture farm of "nori" in heightadjustable mode and height-fixing mode, respectively

likely dominate the nonlinear outburst in the biomass of macroalgae, e.g., the green tides in 2008, while increased nutrient supply would improve the growth rate of macroalgae, and therefore there were more seed population in the Jiangsu Shoal and larger scale of MAB in the Yellow Sea (Smetacek and Zingone 2013).

Due to the limitations in traditional observations as we aforementioned, previous studies (Liu et al. 2012, 2013 and therein) did not observe this process of progressive eutrophication in the study area; however, this evolution in nutrient status is non-ignorable for exploring the reasons for the nonlinear outburst in the expansion of MAB.

\section{Conclusion}

In this study, through the analysis of historical satellite-derived data of Chl- $a$, SST, and PAR as well as the nutrient pollution index (AWCPI-NP) which was derived from the water quality data, we presented the trends of progressive eutrophication in the Yellow Sea where massive floating MAB of $U$. prolifera occur every summer from 2007 . We think that this progressive eutrophication observed over the 2001-2012 period should be included when we exploring the reasons for the nonlinear outburst in the growth of macroalgae, i.e., green tides, in the Yellow Sea since 2007. We also suggest that policy maker should consider this background of increased eutrophication status caused by nutrient input from land for controlling this hazard.

In addition, such world's largest super MAB have been occurring in a semi-enclosed basin, which should alert us to the MAB-associated ecological consequences in the Yellow 
Sea. Results here suggest that the occurrence of drifting macroalgae in the Yellow Sea did not cause the decrease in the annual phytoplankton biomass, but might alter the bloom of phytoplankton in summer and early autumn, and thus more unknown related ecological consequences should be studied.

Acknowledgments This work was supported by projects from the Chinese Academy of Sciences (Nos XDA11020403, XDA11020102, KZCX2-EW-QN209) and the CAS/SAFEA International Partnership Program for Creative Research Teams and the YIC-CAS/ISMAR-CNR cooperation program. We especially thank the Institute of Oceanology, Chinese Academy of Sciences, for organizing the open cruise in the Yellow Sea, and Dr. Yanju HAO and Ms. Mingjing LOU for performing the field sampling, observations, and data collection. We also thank two anonymous reviewers' valuable comments which help to improve this paper.

Open Access This article is distributed under the terms of the Creative Commons Attribution License which permits any use, distribution, and reproduction in any medium, provided the original author(s) and the source are credited.

\section{References}

Carlson RE (1977) A trophic state index for lakes. Limnol Oceanogr 22:361-369

Chen CQ, Tang SL, Pan ZL, Zhan HG, Larson M, Jonsson L (2007) Remotely sensed assessment of water quality levels in the Pearl River Estuary, China. Mar Pollut Bull 54:1267-1272. doi:10.1016/j. marpolbul.2007.03.010

Cui TW et al (2013) Satellite monitoring of massive green macroalgae bloom (GMB): imaging ability comparison of multi-source data and drifting velocity estimation. Int J Remote Sens 33:5513-5527

Egge JK, Aksnes DL (1992) Silicate as regulating nutrient in phytoplankton competition. Mar Ecol Prog Ser 83:281-289. doi:10.3354/Meps083281

Gao XL, Song JM (2005) Phytoplankton distributions and their relationship with the environment in the Changjiang Estuary, China. Mar Pollut Bull 50:327-335. doi:10.1016/j.marpolbul.2004.11.004

Garcia R, Fearns P, Keesing JK, Liu D (2013) Quantification of floating macroalgae blooms using the scaled algae index. J Geophys Res Oceans 118:26-42. doi:10.1029/2012JC008292

Gower J, King S (2011) Distribution of floating Sargassum in the Gulf of Mexico and the Atlantic Ocean mapped using MERIS. Int J Remote Sens 32:1917-1929

Gower J, Young E, King S (2013) Satellite images suggest a new Sargassum source region in 2011. Remote Sens Lett 4:764-773

He Z, Xing Q, Shi H, Pan W (2006) Application of remote sensing technology on regional environment monitoring in Daya Bay. Ecol Sci 25:371-374, 384

Hu C, Li D, Chen C, Ge J, Muller-Karger FE, Liu J, Yu F, He M-X (2010) On the recurrent Ulva prolifera blooms in the Yellow Sea and East China Sea. J Geophys Res 115:C05017. doi:10.1029/ 2009JC005561

JiangSu Provincial Department of Ocean and Fisheries (JSOF) (2011) Bulletin of marine environmental quality of Jiansu Province in 2011

Keesing JK, Liu DY, Fearns P, Garcia R (2011) Inter- and intra-annual patterns of Ulva prolifera green tides in the Yellow Sea during 2007-2009, their origin and relationship to the expansion of coastal seaweed aquaculture in China. Mar Pollut Bull 62:1169-1182. doi:10.1016/j.marpolbul.2011.03.040

Liu D, Keesing JK, Xing Q, Shi P (2009) World's largest macroalgal bloom caused by expansion of seaweed aquaculture in China. Mar Pollut Bull 58:888-895. doi:10.1016/j.marpolbul.2009.01.013

Liu F, Pang S, Chopin T, Gao S, Shan T, Zhao X, Li J (2012) Understanding the recurrent large-scale green tide in the Yellow Sea: temporal and spatial correlations between multiple geographical, aquacultural and biological factors. Mar Environ Res 83:38-47. doi:10.1016/j.marenvres.2012.10.007

Liu D, Keesing JK, He P, Wang Z, Shi Y, Wang Y (2013) The world's largest macroalgal bloom in the Yellow Sea, China: formation and implications. Estuar Coast Shelf Sci 129:2-10

Liu X, Meng R, Xing Q, Lou M, Chao H, Bing L (2014) Assessing oil spill risk in the Chinese Bohai Sea: a case study for both ship and platform related oil spills. Ocean Coast Manag. doi:10.1016/j.ocecoaman. 2014.08.016

Lund JW (1967) Eutrophication. Nature 214:557-558. doi:10.1038/214557a0 
Menesguen A, Cugier P, Leblond I (2006) A new numerical technique for tracking chemical species in a multisource, coastal ecosystem applied to nitrogen causing Ulva blooms in the Bay of Brest (France). Limnol Oceanogr 51:591-601

Ministry of Environmental Protection of China (MEP) (1997) Sea water quality standard (GB3097-1997)

Morand P, Briand X (1996) Excessive growth of macroalgae: a symptom of environmental disturbance. Bot Mar 39:491-516. doi:10.1515/botm.1996.39.1-6.491

O'Reilly JE, Maritorena S, Mitchell BG, Siegel DA, Carder KL, Garver SA, Kahru M, McClain C (1998) Ocean color chlorophyll algorithms for SeaWiFS. J Geophys Res Oceans 103:24937-24953. doi:10. 1029/98jc02160

Pang SJ, Liu F, Shan TF, Xu N, Zhang ZH, Gao SQ, Chopin T, Sun S (2010) Tracking the algal origin of the Ulva bloom in the Yellow Sea by a combination of molecular, morphological and physiological analyses. Mar Environ Res 69:207-215. doi:10.1016/j.marenvres.2009.10.007

Qu M, Xing Q, Pan W (2006) Parameters of monitoring Daya Bay water quality by remote sensing. Ecol Sci 25:262-265

Shi W, Wang M (2009) Green macroalgae blooms in the Yellow Sea during the spring and summer of 2008. J Geophys Res 114:C12010

Smetacek V, Zingone A (2013) Green and golden seaweed tides on the rise. Nature 504:84-88. doi:10.1038/ Nature 12860

State Oceanic Administration of China (SOA) (2010) Bulletin of the marine environmental status of China for the year of 2010

State Oceanic Administration of China (SOA) (2011) Bulletin of the marine environmental status of China for the year of 2011

State Oceanic Administration of China (SOA) (2013) Bulletin of the marine environmental status of China for the year of 2013

UNDP (2007) Fourth meeting of the regional scientific and technical panel for the UNDP/GEF Yellow Sea Project Guangzhou, China, 26-28 Nov 2007

Xing Q, Loisel H, Schmitt F, Shi P, Liu D, Keesing J (2009) Detection of the green tide at the Yellow Sea and tracking its wind-forced drifting by remote sensing. Geophys Res Abstracts 11, EGU2009-577, EGU General Assembly 2009, Vienna

Xing Q, Liu D, Liang S, Yu D, Shi P (2010) Remote Sensing of the transportation of green tide from the aquaculture area of the northern Jiangsu coast to Qingdao of Shandong. Environ Impact Assess China 95(12):10-14

Xing Q, Zheng X, Shi P, Hao J, Yu D, Liang S, Liu D, Zhang Y (2011) Monitoring "Green Tide" in the Yellow Sea and the East China Sea using multi-temporal and multi-source remote sensing images. Spectrosc Spect Anal 31:1644-1647

Xing Q, Loisel H, Schmitt FG, Dessailly D, Hao Y, Han Q, Shi P (2012) Fluctuations of satellite-derived chlorophyll concentrations and optical indices at the Southern Yellow Sea. Aquat Ecosyst Health 15:168-175

Xing Q, Hu C, Tang D, Tian L, Tang S, Wang X, Lou M, Gao X (2015) Super macroalgal blooms altered phytoplankton biomass in the Yellow Sea: satellite observations. Cont Shelf Res (in review)

Yamaguchi H, Kim HC, Son YB, Kim SW, Okamura K, Kiyomoto Y, Ishizaka J (2012) Seasonal and summer interannual variations of SeaWiFS chlorophyll a in the Yellow Sea and East China Sea. Prog Oceanogr 105:22-29

Zhang XW, Xu D, Mao YZ, Li YX, Xue SY, Zou J, Lian W, Liang CW, Zhuang ZM, Wang QY, Ye NH (2011) Settlement of vegetative fragments of Ulva prolifera confirmed as an important seed source for succession of a large-scale green tide bloom. Limnol Oceanogr 56:233-242. doi:10.4319/1o.2011.56.1. 0233

Zhang Z, Zhang X, Xu Z, Yao H, Li G, Liu X (2015) Emergency countermeasures against marine disasters in Qingdao City on the basis of scenario analysis. Nat Hazards 75:s233-s255. doi:10.1007/s11069-014$1332-z$

Zheng X, Xing Q, Shi P, Li L (2011) Numerical simulation of the 2008 green tide in the Yellow Sea. Mar Sci 35:82-87

Zou JZ, Dong LP, Qin BP (1985) Preliminary studies on eutrophication and red tide problems in Bohai Bay. Hydrobiologia 127:27-30 